\title{
Correlation between Substance Use and Anxiety-Depression Spectrum among Senior High School Students in Bandung
}

\author{
Achmad Samjunanto, ${ }^{1}$ Lucky Saputra, ${ }^{2}$ RA. Retno Ekowati ${ }^{3}$ \\ ${ }^{1}$ Faculty of Medicine Universitas Padjadjaran, ${ }^{2}$ Department of Psychiatry Faculty of Medicine \\ Universitas Padjadjaran/Dr. Hasan Sadikin General Hospital Bandung, ${ }^{3}$ Department of Anatomy \\ and Biology Cell Faculty of Medicine Universitas Padjadjaran
}

\begin{abstract}
Background: Both substance use and anxiety-depression spectrum are the problem that currently faced by adolescents especially among Senior High School students. Moreover, there is a high comorbidity between both problems. This study was conducted to discover the substance use's prevalence and to find out anxietydepression spectrum proportion among adolescent, and more importantly to determine whether there is correlation between both variables.

Methods:During October-November 2013, four hundred and fifty two students from five Senior High Schools located in Karees Sub-District, Bandung were included in this cross-sectional analytic study. Among whom, only 425 students filled the questionnaire properly. Data were collected using Kessler-10 (K10) to explore anxiety-depression spectrum and addiction severity index lite version (ASI-Lite) to identify substance use. The correlation between both variables was analyzed by Gamma correlation test.

Results: The study revealed that there were 93 (21.9\%) students that used substance. In addition, there were 244 students (57.4\%) that screened as having anxiety-depression spectrum. Statistical analysis, according to Gamma correlation test, showed that there was a weak correlation between alcohol use and anxiety-depression spectrum ( $\mathrm{p}=0.041 ; \mathrm{r}=0.316)$. The remaining substances gave no statistically significant result ( $\mathrm{p}>0.05)$.
\end{abstract}

Conclusions: There is a high prevalence in substance use and psychological distress in anxiety-depression spectrum among high school student. In addition, alcohol is the only substances that correlated with anxietydepression spectrum. [AMJ,2016;3(4):583-9]

Keywords: Adolescents, anxiety-depression spectrum, high school student, substance use

\section{Introduction}

Senior High School students apparently are adolescents who get a formal education in either state or private Senior High School whose age usually ranges from 14 to 18 years old. Regarding to their development, this age belongs to adolescent phase. Adolescents are people in transition phase from a child phase toward an adult one. ${ }^{1}$ This is a phase of life in which ones try to determine their identity and to explore themselves both socially and psychosexually. ${ }^{1}$ Regarding to their exploration and independency-establishment, there are some problems that arise among adolescent. One of which is substance use that result from risk-taking behavior; a behavior where there is no certainty about its benefits nor harms. Risk-taking behavior actually leads to confidence and competence needed to establish new relationship and to get achievement in either sport, social, or academic. Nevertheless, recently risk-taking behavior is associated with negative behaviors such as careless driving, risky sexual behavior, and especially substance use. ${ }^{1}$

Substance refers to any chemical substances that could affect the process in the human either physically or mentally. ${ }^{1}$ Those substances include alcohol, heroin, methadone, opium, cocaine, amphetamine, cannabis, hallucinogen, inhalant, barbiturate, meth, or any other substances. ${ }^{1}$

Likewise, anxiety and depression is also a prominent adolescents' problem beside the substance use. Some experts stated that there is a common territory between anxiety and depression symptom. ${ }^{2}$ Anxiety-

Correspondence: Achmad Samjunanto, Faculty of Medicine, Universitas Padjadjaran, Jalan Raya Bandung-Sumedang Km.21, Jatinangor, Sumedang, Indonesia, Phone: +6285716571677 Email: samjunanto@gmail.com 
depression spectrum is a symptom of psychological distress and could be measured by an instrument named Kessler- $10 .^{3}$ Among adolescents whose age ranges from fifteen to twenty four years old, there were 8.7 percents prevalence of emotional mental disorder, as stated at riset kesehatan dasar (Riskesdas) $2007,{ }^{4}$ a quinquennial national health survey conducted by Indonesian Ministry of Health. Mental problems that might be faced by highschool student are mood disorder, learning disorder and disruptive behavior disorder. According to study conducted by Pillai et al. ${ }^{5}$ the most common mental disorder that occurred in adolescent were anxiety disorder (54\%), depressive disorder (27\%), behavioral disorder $(24.3 \%)$ and attention deficithyperactivity disorder (10.8\%).

Comorbidity of substance use and mental disorder is quite high. Forty four percents of patients in community mental health team over United Kingdom was reported as an alcohol or substance user. ${ }^{6}$ In addition, a study conducted by Merrill et al. ${ }^{7}$ stated that among overdosed decedents in Utah, anxiety and sadness were the most frequent past psychological disorder they had. Study that correlates both disorders was needed to make a policy regarding those problems' prevention, albeit.There is a lack of such study in Indonesia especially Bandung despite of their high comorbidity. This study, therefore, was conducted to describe the cases of substance use and anxiety-depression spectrum among Senior High School students in Bandung, and more importantly, to determine the correlation between both cases.

\section{Methods}

This analytical cross-sectional study was conducted in five state Senior High Schools in Karees Sub-District, Bandung from October-November 2013 after getting an ethical approval from Health Research Ethics Committee, Faculty of Medicine, Universitas Padjadjaran and permission from Bandung Municipal Government, Bandung Municipal Education Department and also from each school in which this study was conducted. This study was conducted in Karees Sub-District, where highest prevalence of substance abuse was reported based on data from nongovernment organization, named Yayasan Graha Prima Karya Sejahtera (Grapiks) that cooperates with Dr. Hasan Sadikin General Hospital to handle substance abuser. Classes from each school were chosen ramdomly from each grade: grade $\mathrm{X}, \mathrm{XI}$, and XII.

Every student from the chosen classes that satisfied the inclusion criteria and were not excluded based on exclusion criteria was taken as a sample study. The inclusion criteria of this study involved an active student during data collection's period. Absent student, student who refused to be a sample, and student who did not fill in the questionnaire properly were excluded from this study. From fifteen classes, there were only 452 students who met the inclusion criteria, presented at the data collection's day and signed the informed consent with permission of their teacher. Among whom, however, only 425 filled the questionnaire properly.

The questionnaire for this study consisted three parts: identity part, mental health part and substance-use part. Kessler-10 (K-10) was used as an instrument to measure the psychological condition from sample study. $\mathrm{K}-10$ is used to be a non-specific screening test to detect psychological distress based on ten questions about anxiety and depression and it has been validated in Indonesia. ${ }^{3}$ It classifies person into four categories: likely to be well, likely to have mild psychological distress, likely to have moderate psychological distress and likely to have severe psychological distress. Addiction severity index lite version (ASI-Lite) was used to determine the substance use from the sample study. The ASI-Lite is a short version from addiction severity index (ASI) which is a guide for professional mental health worker to interview the client. The ASI involved several aspects such as health status, financial status, substance-abuse status, criminal status, social status and psychiatric status. The ASI-Lite contains 22 fewer questions than the ASI, and omits items related to severity ratings, and a family history grid. ${ }^{8}$

There might be some bias and confounding factors in this study. Student's dishonesty might be one of prominent bias that could be found in this study. This study, therefore, used several steps to minimize it, such as not putting name column in the questionnaire, sealing the questionnaires in opaque envelop before them, asking them to fill the questionnaire alone without involving their teachers, and emphasizing that the result would not be exposed to another person. Some confounding factors that might affect correlation between anxiety-depression spectrum and substance use are age and demographic status., this study used some restriction. This study only conducted in adolescent who currently enrolled formally in Senior-High-School 
Table 1 Sample's Characteristic Profile

\begin{tabular}{lcccc}
\hline \multirow{2}{*}{ Characteristic } & \multicolumn{3}{c}{ Grade } & \multirow{2}{*}{ Total n (\%) } \\
\cline { 2 - 3 } Age (Years old) & $\mathbf{X ~ ( n ) ~}$ & $\mathbf{X I}$ (n) & XII (n) & \\
14 & 7 & & & \\
15 & 83 & 11 & 0 & $8(1.9)$ \\
16 & 9 & 125 & 30 & $164(38.6)$ \\
17 & 1 & 9 & 141 & $151(35.5)$ \\
18 & 0 & 0 & 8 & $8(1.9)$ \\
Gender & 50 & & & \\
Male & 50 & 85 & 65 & $176(41.4)$ \\
Female & & & 114 & $249(58.6)$ \\
Living with & 98 & 139 & 174 & $411(96.7)$ \\
Parents & 2 & 7 & 5 & $14(3.3)$ \\
Other* & $100(23.5)$ & $146(34.4)$ & $179(42.1)$ & 425 \\
Total ** & & & & \\
\hline
\end{tabular}

Note: ${ }^{*}$ Involved living with brother, sister, grandfather, or another relatives, ${ }^{* *}$ The number and percentage in parentheses

academic activity, not to mention only state high school.

Collected data were analyzed by a computerized statistical calculation. Since the variables were ordinal categorical variable and both variables were equal where there were neither dependent nor independent variable, the Gamma correlation test was used in this study to find the $r$ value. The $r$ value measured the correlation power and determined whether the correlation is positive or negative. The $\mathrm{p}$ value was also calculated to determine whether the result is statistically significant. If $p$ value was below $5 \%$, the result was statistically significant. Hence, the null hypotheses could be rejected.

\section{Results}

Among 425 samples, the numbers of female students were higher than male (Table 1). Furthermore, the number of students who had anxiety-depression spectrum was higher than students who used substance (Table 2). Further information about substance user and anxiety-depression spectrum were illustrated in Figure 1 and Figure 2, respectively.

Nicotine, alcohol and cannabis/marijuana were the most used substances with 88 cases (94.6\%), 31 cases $(33.3 \%)$ and 7 cases $(7.5 \%)$ respectively (Figure 1). In addition, there were only 2 cases for methamphetamine user, and only 1 case for each barbiturate, cocaine, amphetamine, hallucinogen, and magic mushroom user. Moreover, there were no heroin, methadone and inhalant users. In addition, the male to female ratio of substance use in this study was 4.5:1.

More than half students were likely to have psychological distress in anxiety-depression spectrum according to K-10 assessment (Figure 2). Yet, only 28 students (6\%) were likely to have severe psychological distress. Moreover, this study revealed that there was $1: 1.6$ as male to female ratio of students that were likely to have anxiety-depression spectrum.

Correlation between the psychological distress in anxiety-depression spectrum and each substance that were used by the sample were determined by Gamma correlation test (Table 3). Among which, only correlation from alcohol use was statistically significant $(\mathrm{p}=0.041)$. The result, however, showed weak correlation between alcohol use and anxietydepression spectrum $(\mathrm{r}=0.316)$. Moreover, beside alcohol, there was no substance that gave a statistically significant result.

\section{Discussion}

Normal range for urinary sodium level is 40$220 \mathrm{mEq} / \mathrm{l}$. In this study, there were 96 subjects from total 111 samples which $86.5 \%$ of them 
Table 2 Anxiety-Depression Spectrum and Substance Use Prevalence Regarding Its Sample's Age, Sample's Grade, Sample's Gender and People Whom Lived with Sample

\begin{tabular}{|c|c|c|c|}
\hline & $\begin{array}{c}\text { Anxiety-depression } \\
\text { spectrum* } \\
\text { n(\%) }\end{array}$ & $\begin{array}{c}\text { Substance Use } \\
\text { n(\%) }\end{array}$ & $\begin{array}{l}\text { Both } \\
\text { n(\%) }\end{array}$ \\
\hline \multicolumn{4}{|c|}{ Age (Years old) } \\
\hline 14 & $7(1.6)$ & $0(0)$ & $0(0)$ \\
\hline 15 & $56(13.2)$ & $15(3.5)$ & $10(2.4)$ \\
\hline 16 & $98(23.1)$ & $32(7.5)$ & $19(4.5)$ \\
\hline 17 & $75(17.6)$ & $44(10.4)$ & $26(6.1)$ \\
\hline 18 & $8(1.9)$ & $2(0.5)$ & $2(0.5)$ \\
\hline \multicolumn{4}{|l|}{ Grade } \\
\hline $\mathrm{X}$ & $62(14.6)$ & $15(3.5)$ & $11(2.6)$ \\
\hline XI & $88(20.7)$ & $31(7.3)$ & $18(4.2)$ \\
\hline XII & $94(22.1)$ & 47 (11.1) & $28(6.6)$ \\
\hline \multicolumn{4}{|l|}{ Gender } \\
\hline Male & $94(22.1)$ & $76(17.9)$ & $44(10,4)$ \\
\hline Female & $150(35.3)$ & $17(4.0)$ & $13(3.1)$ \\
\hline Total & 244 (57.4) & 93 (21.9) & $57(13.4)$ \\
\hline
\end{tabular}

Note: *Everyone except those diagnosed as 'Tikely to be well' by K-10 (likely to have mild, moderate or severe psychological distress in anxiety-depression spectrum),,* Every substances use regardless its substances

had urinary sodium level higher than normal. The percentage of subjects that had normal sodium in urine was $13.5 \%$ from overall samples. The results of urinary sodium level proved that sodium intake among Cipacing resident were still higher than normal limit.

High exposure of sodium in the daily food can make the taste buds adaptation of salt taste perception. ${ }^{5}$ The adaptation makes someone become insensitive with salty taste in low concentration, so he can only taste the saltiness in the higher sodium concentrations. High sodium intake in daily food contributes in high urinary sodium levels. Level of sodium in urine is used as the gold standard for assessing a daily sodium intake.

This study proved the relationship between the threshold of saltiness that can be perceived by the subjects and assessed the levels of sodium intake in the urine $(p<0.01)$. Salt taste threshold is influenced by various factors such as age, history of alcohol and long term drug consumption. ${ }^{6,7}$ Sensitivity of salt taste threshold in elderly will decrease because of reduction sensitivity of sensory function of tongue. ${ }^{8}$ Thus, subjects that were chosen in this study were individuals aged 18-60 years old. ${ }^{9}$ In individuals who consume alcohol also decreased sensitivity of taste because the cytotoxic properties of alcohol can damage the cells. While the decrease sensitivity in the individuals who consume long term drugs (for certain drugs) can cause dry mouth or xerostomia. In this study, to reduce confounding, the individuals who had history of long term drugs consumption or alcohol consumption were eliminated. Results of correlation test showed moderate correlation between urinary sodium levels with salt recognition threshold $(r=0.597$; $\mathrm{p}<0.01$ ). This result shows that the higher the salt recognition threshold will cause the higher sodium levels in urine. Correlation test results also showed moderate correlation between the absolute threshold with urinary sodium levels $(\mathrm{r}=0.407: \mathrm{p}<0.01)$. This showed that the higher the threshold level of saltiness chosen by research subjects in their daily diet, the higher level of sodium they had in their urine. The results of this study had the same results with the study conducted in a teaching hospital Campina, Brazil by Paula et al. ${ }^{10}$ that there was a relationship between the salt taste threshold and sodium in the urine ( $\mathrm{r}=$ vf0.20; $\mathrm{p}=0.046$ ) for recognition threshold and $(\mathrm{r}=0.23 ; \mathrm{p}=0.015)$ for absolute threshold. ${ }^{10}$ 


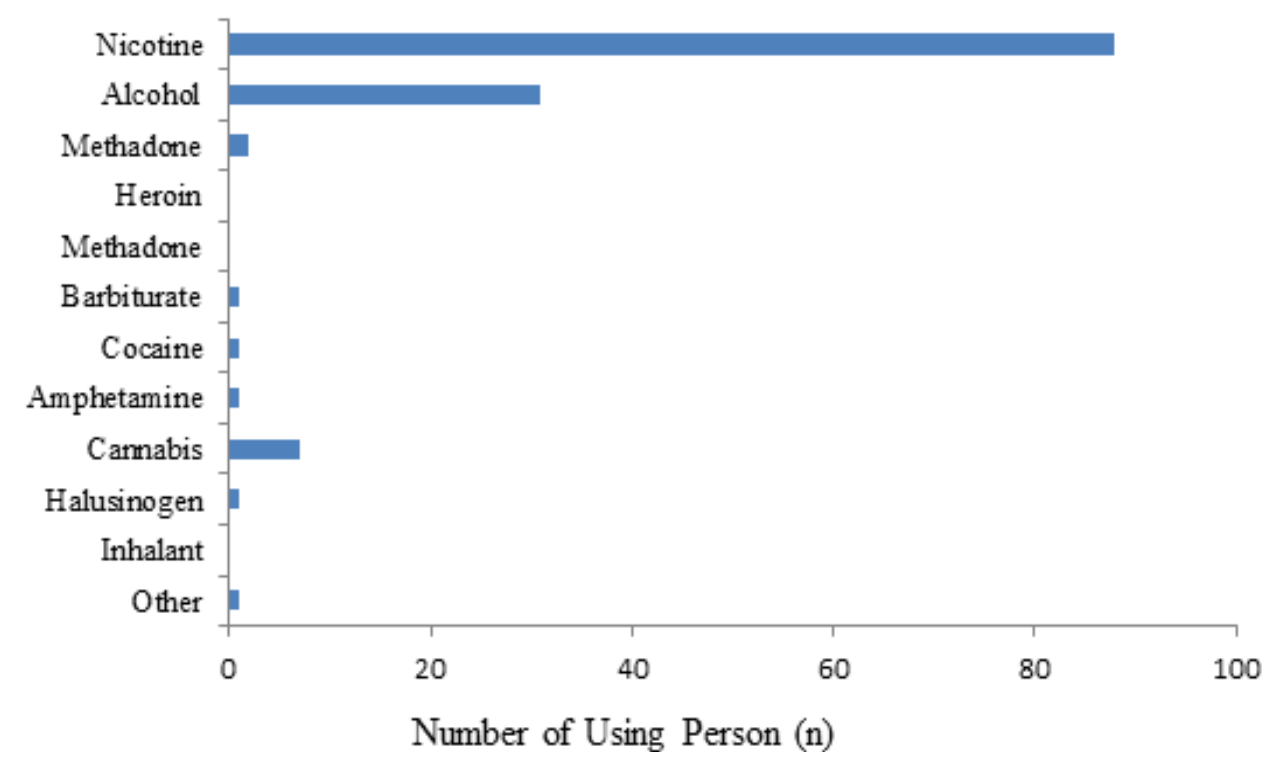

\section{Figure 1 Substance Use Cases Chart Regarding its Type}

This showed that the higher the threshold level of saltiness of the salt solution, the higher the sodium consumed daily. Results of research conducted in Lagos, Nigeria by EC Azinge et al. ${ }^{11}$ with 40 study subjects classified threshold becoming low salt taste threshold and high salt taste threshold. The concentration of salt solution used in the low salt taste threshold was 5-30 $\mathrm{mmol} / \mathrm{l}$ and high salt taste threshold was $60-90 \mathrm{mmol} / \mathrm{l}$. Sodium excreted in the urine for low salt taste threshold was $19.5 \pm 2$ $\mathrm{mmol} / \mathrm{l} / \mathrm{mmol}$ creatinine and 30.3 \pm 0.7 $\mathrm{mmol} / \mathrm{l} / \mathrm{mmol}$ creatinine for high salt taste threshold. ${ }^{11}$

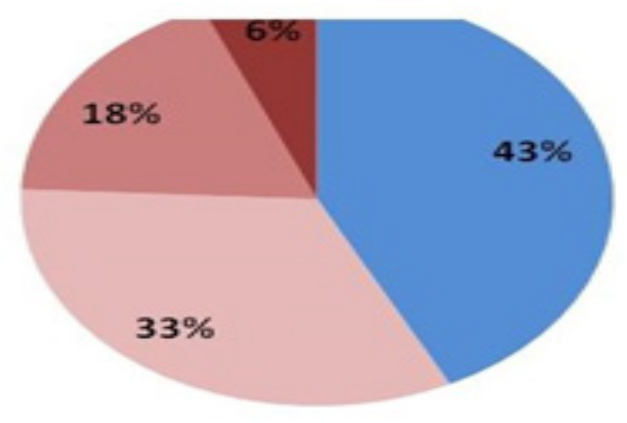

\section{Likely to be well}

Likely to have mild psy chological distress

Likely to have moderate psy chological distress

Likely to have severe psychological distress

Figure 2 Proportion of Anxiety-Depression Spectrum based on Kessler-10 Assessment 
Table 3 Cross-Tabulation Between Anxiety-Depression Spectrum in Anxiety-Depression Spectrum and Substance Use for Each Substance

\begin{tabular}{|c|c|c|c|c|c|c|c|c|}
\hline \multirow{2}{*}{ Substances* } & & \multicolumn{4}{|c|}{ Anxiety-Depression Spectrum } & \multirow{2}{*}{ Total } & \multirow{2}{*}{$\mathbf{p}^{* *}$} & \multirow{2}{*}{$\mathbf{r}^{* * *}$} \\
\hline & & Severe & Moderate & Mild & Well & & & \\
\hline \multirow[t]{2}{*}{ Nicotine } & $(+)$ & 6 & 13 & 34 & 35 & 88 & 0.859 & 0.017 \\
\hline & $(-)$ & 21 & 63 & 107 & 146 & 337 & & \\
\hline \multirow[t]{2}{*}{ Alcohol } & $(+)$ & 4 & 9 & 9 & 9 & 31 & 0.041 & 0.313 \\
\hline & $(-)$ & 23 & 67 & 132 & 172 & 394 & & \\
\hline \multirow[t]{2}{*}{ Methampheta-mine } & $(+)$ & 0 & 1 & 0 & 1 & 2 & 0.894 & 0.086 \\
\hline & $(-)$ & 27 & 75 & 141 & 180 & 423 & & \\
\hline \multirow[t]{2}{*}{ Barbiturate } & $(+)$ & 0 & 0 & 0 & 1 & 1 & 0.316 & -1.0 \\
\hline & $(-)$ & 27 & 76 & 141 & 180 & 424 & & \\
\hline \multirow[t]{2}{*}{ Cocaine } & $(+)$ & 0 & 0 & 0 & 1 & 1 & 0.316 & -1.0 \\
\hline & $(-)$ & 27 & 76 & 141 & 180 & 424 & & \\
\hline \multirow[t]{2}{*}{ Amphetamine } & $(+)$ & 0 & 0 & 0 & 1 & 1 & 0.316 & -1.0 \\
\hline & $(-)$ & 27 & 76 & 141 & 180 & 424 & & \\
\hline \multirow[t]{2}{*}{ Cannabis } & $(+)$ & 0 & 3 & 3 & 1 & 7 & 0.129 & 0.414 \\
\hline & $(-)$ & 27 & 73 & 138 & 180 & 418 & & \\
\hline \multirow[t]{2}{*}{ Hallucinogen } & $(+)$ & 0 & 0 & 1 & 0 & 1 & 0.326 & 0.275 \\
\hline & $(-)$ & 27 & 76 & 140 & 181 & 424 & & \\
\hline \multirow[t]{2}{*}{ Other (magic mushroom) } & $(+)$ & 0 & 0 & 0 & 1 & 1 & 0.316 & -1.0 \\
\hline & $(-)$ & 27 & 76 & 141 & 180 & 424 & & \\
\hline \multirow[t]{2}{*}{ Multisubstance ${ }^{* * * *}$} & $(+)$ & 3 & 8 & 9 & 10 & 30 & 0.159 & 0.218 \\
\hline & $(-)$ & 24 & 68 & 132 & 171 & 395 & & \\
\hline Total & & 28 & 27 & 76 & 141 & 181 & & \\
\hline
\end{tabular}

Note: *Heroin, inhalant and methadone was not included since the absence of user,**The result was statistically significant if $\mathrm{p}<0.05$, ${ }^{* * *}$ The $r$ described the correlation power (0.00-0.199: very weak; 0.20-0.399: weak; 0.4-0.599: fair; 0.6-0.799: strong; 0.8-1.00: very strong), ${ }^{* * * *}$ Substance usage more than 1 substance

Levels of sodium in the body vary every time. Standards used to assess the levels of sodium in the body were a 24 hours urine laboratory tests. However, in this study, that was not carried out and only used the predicted urine 24 hours using the Tanaka's formula. Tanaka's study used laboratory results of urine in the morning and afternoon because the difficulty of collecting urine for 24 hours as well as the inconvenience of research subjects to collect urine for 24 hours. The reason for using predicted formula by Tanaka et al..$^{12}$ in this study was due to the fact that subject of research studies on the formula Tanaka were Asians that had resembled characteristics with the subjects in this study which were Indonesians.

Limitations of this study was the result of calculation of predicted 24 hours urinary sodium in the urine results as inadequate to accurately estimate the amount of sodium intake of a person because there was a difference in the results of which approximately $24.0 \mathrm{mmol} /$ day. ${ }^{13}$ Suggestion that could be given based on this research was further using the results of sodium in urine for 24 hours. In addition, the researchers did not supervise the subject of research in decision urine in the morning and evening, so that researchers could not guarantee that the research subjects had collected urine samples with the correct method.

Advices to be given based on this research are to health workers who can help the villagers of Cipacing to regulate the amount of sodium intake in their daily diet. Health workers can quickly detect the sodium intake of salty taste threshold of someone by using salt taste threshold. Rapid detection of the sodium intake is expected to reduce the incidence of hypertension by modifying risk factors. ${ }^{14}$ Controlled sodium intake to 
minimize the incidence of hypertension due to a reduction in sodium intake of $77 \mathrm{mmol} /$ day can lower systolic blood pressure $1.9 \mathrm{mmHg}$ and $1.1 \mathrm{mmHg}$ diastolic.

From this study, it can be concluded that there is moderate correlation of salt taste threshold and urinary sodium excretion which mean subjects that have high salt taste threshold may have high sodium intake.

\section{References}

1. Sadock BJ, Sadock VA. Kaplan \& Sadock's comprehensive textbook of psychiatry. 9th ed. Philadelphia: Lippincott Williams \& Wilkins; 2009

2. Andreescu C, Lenze EJ. Comorbid anxiety and depression: bête noire or quick fix? $\mathrm{Br}$ J Psychiatry. 2012;200(3):179-81.

3. Kessler RC, Andrews G, Colpe LJ, Hiripi E, Mroczek DK, Normand SL, et al. Short screening scales to monitor population prevalences and trends in non-specific psychological distress. Psychol Med. 2002;32(6):959-76.

4. Badan Penelitian dan Pengembangan Kesehatan. Riset kesehatan dasar 2007. Jakarta: Departemen Kesehatan RI; 2008

5. Pillai A, Patel V, Cardozo P, Goodman R, Weiss HA, Andrew G. Non-traditional lifestyles and prevalence of mental disorders in adolescents in Goa, India. Br J
Psychiatry. 2008;192(1):45-51

6. Weaver T, Madden P, Charles V, Stimson G, Renton A, Tyrer P, et al. Comorbidity of substance misuse and mental illness in community mental health and substance misuse services. Br J Psychiatry. 2003; 183:304-313

7. Merrill RM, Johnson EM, Sloan A, Lanier WA. Characterizing unintentional nonillicit and illicit substance-related deaths. Journal of Drug Issues. 2013;43(2):144-53.

8. Cacciola JS, Alterman AI, McLellan AT, Lin Y-T, Lynch KG. Initial evidence for the reliability and validity of a "lite" version of the addiction severity index. Substance Alcohol Depend. 2007;87(2):297-302.

9. Rohrbach LA, Sussman S, Dent CW, Sun P. Tobacco, alcohol, and other substance use among high-risk young people: a fiveyear longitudinal study from adolescence to emerging adulthood. Journal of Drug Issues. 2005;35(2):333-56.

10. Miller JW, Naimi TS, Brewer RD, Jones SE. Binge drinking and associated health risk behaviors among high school students. Pediatrics. 2007;119(1):76-85.

11. Blanchard LT, Gurka MJ, Blackman JA. Emotional, developmental, and behavioral health of american children and their families: a report from the 2003 national survey of children's health. Pediatrics. 2006;117(6):e1202-e12. 